\title{
Pintando as masculinidades latino- americanas pela perspectiva pós-colonial e interseccional
}

Painting Latin American Masculinities from a Postcolonial and Intersectional Perspective

Roberta Silveira Pamplona ${ }^{1}$ (i) 0000-0003-2259-7904

'Universidade Federal do Rio Grande do Sul, Programa de Pós-Graduação em Sociologia, Porto Alegre, RS, Brasil. 91501-970 - atendimento-ppgifch@ufrgs.br

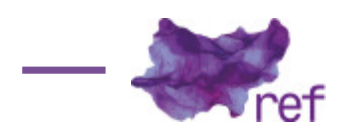

VIVEROS, Mara.

As cores da masculinidade. Experiências internacionais e práticas de poder na Nossa América.

Trad. de Allyson de Andrade Perez. Belo Horizonte: Papéis Selvagens, 2018.

\begin{abstract}
Em meio aos inúmeros debates acadêmicos e políticos sobre a atuação dos homens na luta pela igualdade de gênero, As cores da masculinidade: experiências internacionais e práticas de poder na Nossa América de autoria da antropóloga colombiana Mara Viveros Vigoya, traduzida e editada pela Papéis Selvagens em 2018, apresenta argumentos essenciais para esses debates. Os estudos descritos como de gênero, frequentemente, produzem análises que consideram apenas a construção e a posição dos femininos na sociedade, desconsiderando, aparentemente, que o gênero é relacional, sendo, portanto, indispensável um olhar atento ao seu par: as masculinidades.

Com um prefácio cuidadoso da socióloga australiana Raewyn Connell, que também ocupa um lugar importante nos estudos sobre as masculinidades, a obra é inscrita nas epistemologias pós-coloniais, revelando uma análise das relações de gênero localizadas em contextos específicos e, simultaneamente, pensadas em relação ao contexto global. De fato, sua leitura possibilita o reconhecimento da perspectiva pós-colonial como pano de fundo, visto que a própria autora se apresenta como uma mulher negra colombiana e, assim, aponta a própria localidade da produção do seu conhecimento. Ademais, Mara Viveros é professora no Departamento de Antropologia e na Escola de Estudos de Gênero da Universidade Nacional da Colômbia, o que demarca sua atuação acadêmica no contexto latino-americano.

O volume está dividido em duas partes: "Teorias feministas e masculinidades", e "Masculinidades nossamericanas", respectivamente. Em linhas gerais, a primeira seção traça as principais discussões da teoria feminista para analisar a dominação masculina, buscando situar os estudos sobre homens e masculinidades dentro dessas teorias. A segunda parte, com forte embasamento histórico e que busca explicações desde os textos coloniais sobre o continente, trata dos imaginários sociais sobre o masculino na América Latina, bem como seus desdobramentos, rupturas e continuidades até os dias atuais.

Para compreender a complexa relação entre as teorias feministas e os estudos sobre as masculinidades na primeira parte do livro, Viveros, no capítulo "Para além do binarismo", retoma
\end{abstract}


a emergência dos estudos sobre masculinidades e suas principais conclusões, apontando o masculino como uma construção social que se transforma conforme as pessoas, as sociedades e as épocas, não sendo, portanto, uma qualidade essencial. Em sua análise, Viveros argumenta a importância do Black Feminism dentro dos estudos de masculinidades, justamente por reconhecerem as diferentes identidades masculinas possíveis.

Ao tratar dos estudos sobre masculinidades no mundo atual, a autora retoma os complexos meandros sobre a masculinidade moderna, a qual se inscreve em uma dominação masculina reacionária, pautada por um sentimento de perda de poder dos homens na atualidade. Para tanto, a antropóloga analisa estudos clássicos da masculinidade como a obra de Michael Kimmel (2008) e de Raewyn Connell (1995). Como forma de concluir a relação entre teorias feministas e masculinidades, a estudiosa defende a necessidade de assumir uma perspectiva teórica-política em que se considerem o gênero como "uma categoria relacional que dá conta de uma ampla dinâmica social na qual formas de dominação interagem em diferentes escalas (macro e micro)" (Mara VIVEROS, 2018, p. 59).

No segundo capítulo - "Trinta anos de estudos sobre homens e masculinidades na Nossa América" -, Viveros se propõe à tarefa de compreender quais são os principais resultados dos estudos das masculinidades na América Latina. Por meio de um esforço de síntese, que incluiu a coleta de publicações em bases de dados como a Scielo e a Biblioteca Digital Feminista, Viveros analisa diversas obras produzidas a partir dos anos de 1980 por meio de dois recortes temporais: o primeiro compreende as publicações encontradas entre 1980 e 1990, de maneira a retomar parte de um estado da arte publicado pela autora em 2002; o segundo levantamento corresponde aos quinze anos seguintes (entre 1990 e 2005). O trabalho de fôlego realizado pela autora neste capítulo resulta em dados gerais da produção sobre masculinidades na América Latina. A partir disso, Viveros identifica as principais temáticas abordadas pelos estudos organizando-as em sete eixos (VIVEROS, 2018, p. 67): i) identidades masculinas; ii) masculinidades e violências; iii) problemas, dilemas e tensões em torno da saúde dos homens; iv) afetos e sexualidades; v) reflexões epistemológicas sobre os estudos das masculinidades; vi); representações e produções culturais das masculinidades; e vii) homossociabilidade masculina.

Entre as discussões, a autora trata com mais profundidade sobre o uso de expressões como "machismo latino-americano" (VIVEROS, 2018, p. 93) que mistificam e naturalizam o machismo, apoiando-se em estereótipos de classe, raça e sexo. Como forma potente de repensar essa mistificação, a antropóloga defende que os relatos envolvendo masculinidades locais devem ser confrontados e vinculados com "os processos coloniais, neocoloniais e os do liberalismo econômico" (VIVEROS, 2018, p. 94). Para tanto, recorrendo aos argumentos de Connell encontrados em Southern Theory (2007), elabora sobre a necessidade de as pesquisas latino-americanas deixarem de ser exportadoras de matéria-prima de conhecimento para ocuparem espaço de produção de conhecimento válido. A reflexão final dessa primeira parte do volume está na urgência de pesquisas voltadas aos estudos sobre as masculinidades latino-americanas, visto que permitem entender a multiplicidade de experiências masculinas.

Na segunda parte do livro, com ênfase às masculinidades nossamericanas, Viveros trata dos corpos negros e da construção da imagem de tais corpos. Para tanto, apresenta em "Corpos negros masculinos: mais além ou mais aquém da pele", por meio de exemplos históricos, como o homem negro foi e é descrito, pelo imaginário das pessoas brancas, como um ser dionisíaco, centrado no gozo, na dança e no álcool. A complexidade da questão é aprofundada quando essas características são tomadas como forma de resistência e de manifestação cultural, propondo questões sobre estratégias de ressignificar esses imaginários. Viveros demonstra e analisa esse fenômeno - e a sua potencialidade - através de exemplos de grupos de música e de dança atuais. Ainda que não seja proposto diretamente pela autora, é interessante pensar como a reflexão apresentada pela pesquisadora também é compatível com outros estereótipos construídos que, hoje, são ressignificados pelos sujeitos em que esses imaginários recaem, mostrando um caminho possível de mudança para esses sujeitos.

Com o título "Os benefícios da masculinidade branca", o quarto capítulo aborda o tema da masculinidade na sua interface com a questão da branquitude. Novamente, a autora reconstrói aspectos do colonialismo - como a ideia de certificado de "pureza do sangue" (VIVEROS, 2018, p. 134) - para explicar a hierarquização social, especialmente sua faceta da racialização. Dessa forma, a ideia de harmonia racial é apoiada no imaginário do homem branco como sinônimo de civilidade, progresso e modernidade. Conjuntamente, a autora complexifica a questão ao tratar do conceito de nação mestiça - muito utilizado por países latino-americanos - em que as categorias sociais tentam ser apagadas, ainda que continuem moldando as relações. Nesse contexto, os movimentos sociais indígena e negro atuam de forma contundente para o reconhecimento dos privilégios da branquitude.

Em contraste com o restante do livro, nos quais articula obras, estudos e exemplos com outros países, Viveros utiliza muito mais exemplos e fenômenos históricos colombianos para 
compreender a construção e as estratégias de manutenção dos privilégios por parte dos homens brancos. Ao retomar a história do ex-presidente colombiano Álvaro Uribe, que considerava os problemas de exclusão social serem decorrentes de questões meramente socioeconômicas e não por questões raciais (VIVEROS, 2018, p. 151), a autora poderia ter incluído ainda outros exemplos similares de discurso e de política no continente a fim de reforçar as similitudes latino-americanas como realizado em outras seções.

O capítulo final é dedicado à temática do continuum da violência na América Latina. Ao propor que a violência masculina para com as mulheres está inscrita na origem da história colonial do continente, Viveros relaciona uma violência de tipo estrutural - imbricada no processo colonizador - e seus efeitos em violências íntimas, domésticas e simbólicas. Entretanto, essa relação descrita pela antropóloga não é interpretada como simples traço cultural latino-americano, visto que há no texto o cuidado de demonstrar essa dimensão sociocultural circunscrita pelas relações de poder e de economia do contexto global, acionando o conceito de colonialidade do poder nos termos de Aníbal Quijano (2000).

Ao exemplificar como historicamente foram construídas masculinidades subordinadas em relação aos colonizadores, Viveros traz à tona as tensões de gênero não apenas entre homens e mulheres, mas entre homens e homens. Isto é, questiona as diferentes formas de expressar as tensões sociais, posto que alguns homens agem de modo mais violento que outros. Assim, evoca a necessidade de considerar as relações intragênero ao refletir sobre essas diferenças. A resposta para essas reflexões é a interseccionalidade, que não é utilizada por Viveros como simples soma de marcadores sociais, mas como categorias construídas historicamente que recaem em determinados corpos e, com isso, produzem subjetividades distintas dentro de cada contexto.

Em muitos países, a resposta para o continuum da violência é a mudança legislativa em que se criminaliza a violência de gênero com penas mais duras. A antropóloga faz a crítica para o fato de que muitas legislações estão em permanente tensão com valores culturais presentes entre os próprios operadores do sistema de justiça criminal, motivo pelo qual poucas mudanças ocorrem efetivamente às vítimas. Isso acontece, pois, as mudanças legislativas não necessariamente diminuíram essas violências ou resultaram em um melhor tratamento concedido às vítimas pelas instituições estatais. Entretanto, Viveros não aponta, em sua análise, como esses valores culturais também resultam em tratamentos distintos para os autores, sendo que determinados atos são reconhecidos ou não como violentos em função da pessoa que pratica violência, e não somente em função da vítima.

Para sintetizar a sua análise e situar o percurso escolhido para o debate empreendido, a autora retoma os principais pontos que buscou desenvolver, entre os quais está a complexa relação dos homens com o feminismo e, consequentemente, a potencialidade dos trabalhos sobre homens realizados a partir da América Latina, na medida que permitem criticar o universalismo sobre as masculinidades. Isto é, ser homem não decorre apenas de relações de gênero, mas está imbricado pelas relações raciais, geográficas e históricas. Com isso, a própria consideração sobre a participação dos homens na igualdade de gênero significa reconhecer as múltiplas formas possíveis de masculinidades e como são tensionadas pelas mudanças nas relações de gênero. Nesse ponto, Viveros retoma o entendimento de que as relações de gênero estão em constante dinamicidade, sendo dependentes das próprias ações e reações das forças que elas implicam. Por fim, vale dizer que a dinamicidade dessas relações é constatada e apontada pela autora ao lançar mão de diferentes estudos e pesquisas a fim de demonstrar importantes mudanças nas relações afetivas e sexuais dos homens.

No fechamento da obra, Viveros retoma a crítica de modelos generalizantes de análise que ignoram a dimensão relacional do gênero. Afirma que o trabalho investigativo deve compreender as masculinidades em conexão com as feminilidades e, também, considerar a existência de uma autoconexão - a relação de homens com outros homens. Além disso, estabelece a ligação da dimensão de gênero com outras estruturas de dominação e com dinâmicas sociais mais amplas e globais, posicionando os corpos e suas práticas sociais em um nível macrossocial de análise. A obra de Mara Viveros permite ampliar horizontes nos estudos de masculinidades no Brasil propondo análises interseccionais sobre o masculino e, ainda, análises que busquem explicar as diferentes masculinidades brasileiras. A compreensão dessas diferenças exige um desenho metodológico intracategorial - entre as formas do masculino. Atualmente, os estudos sobre as múltiplas experiências femininas demonstram as vantagens em considerar os diferentes eixos sociais que moldam os sujeitos. Tais vantagens estão circunscritas em análises interseccionais e pós-coloniais. Ao fim, Mara Viveros dá cores às diferentes experiências de masculinidade - pintando de forma cuidadosa as nuances que circunscrevem o tema - que muitas vezes são vistas de forma opaca como uma única masculinidade.

\section{Referências}

CONNELL, Raweyn. Masculinities. Cambridge: Polity Press, 1995. 
CONNELL, Raweyn. Southern Theory: The Global Dynamics of Knowledge in Social Science. Cambridge: Polity Press, 2007.

KIMMEL, Michael. "Los estudios de masculinidad: una introducción”. In: VALDÉS, Teresa; OLAVARRÍA, José (Orgs.). Masculinidad/es: poder y crisis. Barcelona: Icaría, 2008, p. 15- 32.

QUIJANO, Aníbal. "La colonialidad del poder, eurocentrismo y América Latina”. In: LANDER, Edgardo. La colonialidad del saber: eurocentrismo y ciencias sociales. Buenos Aires: CLACSO, 2000, p. 201246.

VIVEROS, Mara. As cores da masculinidade. Experiências internacionais e práticas de poder na Nossa América. Trad. de Allyson de Andrade Perez. Belo Horizonte: Papéis Selvagens, 2018.

Roberta Silveira Pamplona (pamplona.roberta@gmail.com) é mestranda do Programa de Pós-Graduação em Sociologia da Universidade Federal do Rio Grande do Sul com bolsa do CNPq e período sanduíche no Departamento de Sociologia da Universidade de Toronto. Bacharela em Ciências Jurídicas e Sociais pela mesma Universidade, faz parte do grupo de pesquisa Violência e Cidadania (GPVC) e tem interesse nos seguintes temas: relações de gênero; feminicídios; e violência na América Latina.

\section{COMO CITAR ESSE ARTIGO DE ACORDO COM AS NORMAS DA REVISTA}

PAMPLONA, Roberta Silveira. "Pintando as masculinidades latino-americanas pela perspectiva pós-colonial e interseccional". Revista Estudos Feministas, Florianópolis, v. 28, n. 1, e62653, 2020.

\section{CONTRIBUIÇÃO DE AUTORIA}

Não se aplica.

\section{FINANCIAMENTO}

Conselho Nacional de Desenvolvimento Científico e Tecnológico - CNPq.

\section{CONSENTIMENTO DE USO DE IMAGEM}

Não se aplica.

\section{APROVAÇÃO DE COMITÊ DE ÉTICA EM PESQUISA}

Não se aplica.

\section{CONFLITO DE INTERESSES}

Não se aplica.

\section{LICENÇA DE USO}

Este artigo está licenciado sob a Licença Creative Commons CC-BY International. Com essa licença você pode compartilhar, adaptar, criar para qualquer fim, desde que atribua a autoria da obra.

HISTÓRICO

Recebido em 23/03/2019

Revisões requeridas em 12/06/2019

Aprovado em 30/1 1/2019 